\title{
Properties of Reactive Powder Concrete and Its Application in Highway Bridge
}

\author{
Junwei Song ${ }^{1,2}$ and Shuhua Liu ${ }^{1,2}$ \\ ${ }^{1}$ Nanchang Key Laboratory of Material and Structure Detection, Jiangxi University of Technology, Nanchang 330098, China \\ ${ }^{2}$ State Key Laboratory of Water Resources and Hydropower Engineering Science, Wuhan University, Wuhan 430072, China \\ Correspondence should be addressed to Shuhua Liu; shliu@whu.edu.cn
}

Received 26 October 2015; Revised 4 January 2016; Accepted 11 January 2016

Academic Editor: Osman Gencel

Copyright (c) 2016 J. Song and S. Liu. This is an open access article distributed under the Creative Commons Attribution License, which permits unrestricted use, distribution, and reproduction in any medium, provided the original work is properly cited.

\begin{abstract}
A high-performance reactive powder concrete (RPC) was prepared with river sand, and the maximum particle size is $1.25 \mathrm{~mm}$, under the $80^{\circ} \mathrm{C}$ steam curing condition. It is tested completely in terms of strength, uniaxial compressive stress-strain relation, flexural load-deflection relation, and frost resisting durability, and the results indicate that the concrete is suitable to RPC200. The uniaxial compressive stress-strain curve shows a linear-elastic behaviour up to explosive failure, which is different from that of conventional concrete. High postpeak load carrying capacity shows high toughness and reinforcing effect of the steel fibers. The RPC has not only much higher limit strain than conventional concrete, but also excellent frost resisting durability at the fifth day of age exceeding F300. Furthermore, the RPC satisfactorily meets the requirement of practical application for Xialouzi Bridge built with the RPC totally according to the calculation with finite element analysis software MIDAS/Civil. And the static loading testing result suggests that design of the bridge meets the utilization requirements.
\end{abstract}

\section{Introduction}

In 1993, French Corporation BOUYGUES firstly developed a new type of ultra-high-performance cement based composite material-reactive powder concrete (RPC) [1-3]. Though it has not been long since its advent, RPC has already been successfully applied in engineering construction field in a few years, due to its high mechanical properties and excellent durability. The first footbridge made of RPC in the world locates in Sherbrooke, Québec Province, Canada. It adopts truss structure of RPC steel tube in $60 \mathrm{~m}$ width. Stainless steel tube loaded with RPC200 is used to make the web member of the truss structure. The lower chord is RPC twin beams. Each of the prefabricated sections is $10 \mathrm{~m}$ long and $3 \mathrm{~m}$ high and they are assembled together through posttensioned prestressing after being transported to the site [4]. The use of RPC not only mitigates weight greatly but also improves the structure's durability to resist the frequent corrosion from the deicing salt and damage due to the freezing and thawing cycle under environments with high humidity. RPC is a kind of ultra-high-performance concrete with high strength, high tenacity, and low porosity. Enhancing the components' fineness and activity and abandoning coarse aggregate to minimize the material's internal defect (pore space and microcrack) are main basic preparation principles to attain ultra-high strength and durability [5-10].

RPC possesses very high strength: it is usually divided into two grades: RPC200 and RPC800. The former's compressive strength and tensile strength are 170-230 MPa and 20$50 \mathrm{MPa}$, respectively, and those of the latter are $500-800 \mathrm{MPa}$ and 45-140 MPa, respectively [4]. As for the good tenacity, incorporating steel fiber could increase the RPC's fracture energy to $20000-40000 \mathrm{~J} / \mathrm{m}^{2}$. In comparison with ordinary concrete, the rupture strength of RPC is an order of magnitude higher, and the fracture energy is more than two orders of magnitude higher [11-13]. Moreover, its low w/b ratio producing good pore structure and low porosity contributes to RPC's excellent durability $[14,15]$.

RPC is soon widely spread in European and American countries for its excellent properties in the last two decades. The Mars Hill Bridge in Iowa, USA, built by Lafarge Corporation using Ductal ${ }^{\circ}$ material is a successful example. Completely 
constructed by using RPC, the bridge won The Tenth Bridge Competition Award held by American PCI Association and was honored to be "The future bridge" [4].

But, there are many limits in these mentioned bridges. The first RPC bridge of Sherbrooke is a pedestrian bridge, and the load-bearing capability of these pedestrian bridges is very low. What is more, most of the highway RPC bridges were built with reinforced or even prestressed RPC, and the reinforcement ratio reduces little, which does not make the best of its advantages of ultra-high strength and high toughness.

According to Xialouzi Bridge engineering project, RPC200 was prepared. Its strength, compressive stress-strain behaviour, flexure load-deflection character, and durability were tested. The bridge was built with plain RPC and without any reinforcement to take full advantage of its ultra-high strength, toughness, and durability. The RPC satisfactorily meets the requirement of practical application for Xialouzi Bridge built by RPC totally according to the calculation with finite element analysis software MIDAS/Civil.

\section{Experimental}

P.O 42.5 ordinary Portland cement, ultrafine active silica fume, river sand (the maximum particle diameter is $1.25 \mathrm{~mm}$ ), superplasticizer, steel fiber $(12-15 \mathrm{~mm}$ long, the diameter is $0.2-0.25 \mathrm{~mm}$, and tensile strength exceeds $2850 \mathrm{MPa}$ ), and tap water were used. Table 1 shows the mix proportion of RPC200.

A forced mixer is the mixing machine for RPC preparation. Mix the sand, cement, and silica fume for 2 minutes under dry condition; pour the superplasticizer and water and mix for 5 minutes; finally add the steel fiber and mix for 3-6 minutes. Cast RPC into the mould for 24 hours. Then remove the mould and put RPC in the curing box under $80^{\circ} \mathrm{C}$ steam curing condition for 72 hours. After that, let them cool naturally in the curing box for 24 hours and conduct performance test. The whole period lasts five days after adding the mixing water.

\section{Properties of RPC200}

3.1. Strength. Prepare RPC according to the above mix proportion and test its compressive strength, flexure strength, elastic module, splitting tensile strength, and shear strength. Table 2 lists the test results. There are three various kinds of specimen size for the compressive strength test: $40 \times 40 \times$ $40 \mathrm{~mm}, 100 \times 100 \times 100 \mathrm{~mm}$, and $100 \times 100 \times 300 \mathrm{~mm}$, marked with 4,10 , and 10 prismoids, respectively; specimens 4 and 10 are for flexural strength test and 10 prismoids for elastic module test, and 10 is for splitting tensile strength test and shear strength test.

As is shown in Table 2, compressive strengths of cubic RPC specimens of $4 \mathrm{~cm}$ size and $10 \mathrm{~cm}$ size are $236.8 \mathrm{MPa}$ and 218.3 MPa, both meeting RPC200 requirement. In addition, tensile strength and flexure strength are so high that both are exceeding $25 \mathrm{MPa}$; the elastic module is $48.9 \mathrm{GPa}$ and according to these test results, RPC200 is suitable for the bridge structure.
TABLE 1: Mix proportion of RPC200/ $\mathrm{kg} \cdot \mathrm{m}^{-3}$.

\begin{tabular}{lccccc}
\hline Cement & Silica fume & Water & Superplasticizer & Sand & Steel fiber \\
\hline 884.3 & 221.1 & 148.2 & 27.6 & 1105.4 & 150.0 \\
\hline
\end{tabular}

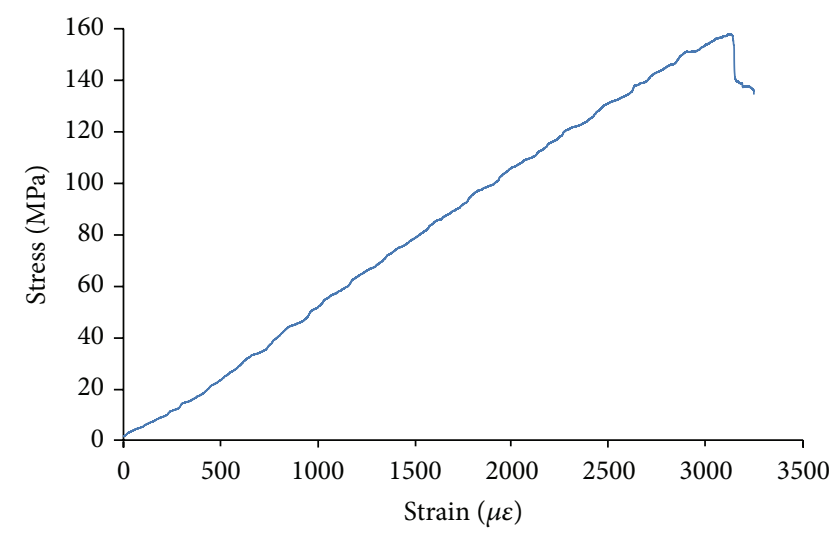

Figure 1: Compressive stress-strain curve of RPC200 (R).

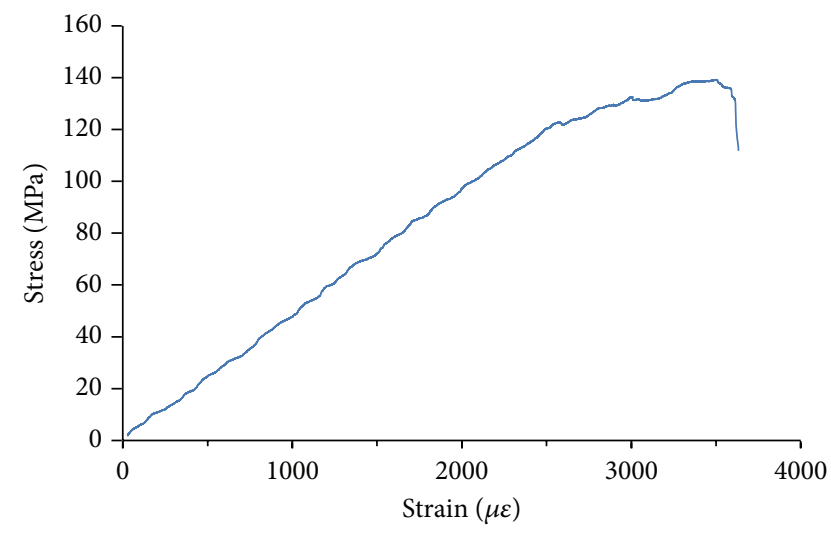

FIgURE 2: Compressive stress-strain curve of RPC200 (S).

3.2. Stress-Strain Behaviour. $100 \times 100 \times 300 \mathrm{~mm}$ prismatic specimens were tested in the compressive stress-strain curve experiment. Displacement control loading type is adopted, and the loading rates are $10^{-4} / \mathrm{s}$ (marked with " $R$ ") and $10^{-5} / \mathrm{s}$ (marked with " $S$ "), respectively. $100 \times 100 \times 400 \mathrm{~mm}$ prismatic specimens were tested in flexural stress-deflection curve experiment. Displacement control loading type is also adopted, and the loading rate is $10^{-4} / \mathrm{s}$.

3.2.1. Compressive Stress-Strain Behaviour. Compressive stress-strain curves of RPC are shown as in Figures 1 and 2. It could be inferred from them that the compressive stressstrain characteristic of RPC200 displays obviously brittle failure. In both stress-strain curves of different loading rates, the stress of RPC200 increases straight as the strain increases until explosive failure so the descending stage could not be observed. 
TABLE 2: Mechanical properties of RPC200.

\begin{tabular}{lccccccc}
\hline \multicolumn{3}{c}{ Compressive strength/MPa } & \multicolumn{2}{c}{ Flexural strength/MPa } & Elastic module/GPa & Splitting tensile strength/Mpa & Shear strength/MPa \\
4 & 10 & 10 prismoids & 4 & 10 & 48.9 & 25.6 & 19.1 \\
\hline 236.8 & 218.3 & 151.3 & 31.4 & 27.7 & & & \\
\hline
\end{tabular}

TABLE 3: Characteristic parameters of compressive stress-strain curves of RPC200.

\begin{tabular}{lcc}
\hline Loading rate & Peak strain/ $\mu \varepsilon$ & Ultimate stress/MPa \\
\hline $10^{-4} / \mathrm{s}$ & 3129 & 158 \\
$10^{-5} / \mathrm{s}$ & 3508 & 140 \\
\hline
\end{tabular}

Table 3 lists the characteristic parameters of compressive stress-strain curve of RPC200. Ultimate strength of the RPC under $10^{-4} / \mathrm{s}$ loading rate is $18 \mathrm{MPa}$ higher than that under $10^{-5} / \mathrm{s}$ loading rate. The faster the loading rate, the higher the ultimate strength, which is consistent with ordinary concrete (strain $(\mu \varepsilon)$, stress $(\mathrm{MPa}))$.

3.2.2. Flexural Load-Deflection Curve. The flexural load-deflection curve test adopted three-point bending load method and the span across the bottom pivot is $300 \mathrm{~mm}$. Figure 3 displays the flexural load-deflection curve. It reveals that the flexural load-deflection curve displays favourable ductility, and the descending stage is very gentle. Extraction or tensile failure of the steel fiber should account for the curve's jumping part, but the whole still presents good ductility.

3.2.3. Constitutive Model. Unlike ordinary concrete, lack of coarse aggregate renders better uniformity of RPC for influence of the transition zone is little, and its constitutive relationship is similar to that of mortar. Judging from the previous test results and analysis, RPC is a typical elastic brittle material. In the RPC prismatic specimens' uniaxial compressive strength test, the stress-strain curve displays a linear ascent stage until the ultimate strain when the strength sharply drops, and then explosive failure occurs finally. So it is difficult to observe complete descending stage. The uniaxial compressive stressstrain relationship of RPC could be expressed as follows:

$$
\begin{aligned}
& \sigma_{c}=E_{c} \varepsilon_{c} \quad\left(\varepsilon_{c} \leq \varepsilon_{0}\right), \\
& \sigma_{c}=0 \quad\left(\varepsilon_{c}>\varepsilon_{0}\right) .
\end{aligned}
$$

The elastic module of RPC is $40 \sim 50 \mathrm{GPa}$ according to different researchers' tests. In this paper, the elastic module of RPC200 is $48.9 \mathrm{GPa}$. Elastic module of RPC relates to its matrix strength and amount of steel fiber. Besides, elastic module increases to some extent when the loading rate is fast. Compared with ordinary concrete, when strength of RPC increases a lot, its elastic module changes a little. Thus, the ultimate strain of RPC is far higher than ordinary concrete, usually 3000 5000 microstrains, and even exceeds steel's yielding strain, while that of ordinary concrete is 1500 2000.

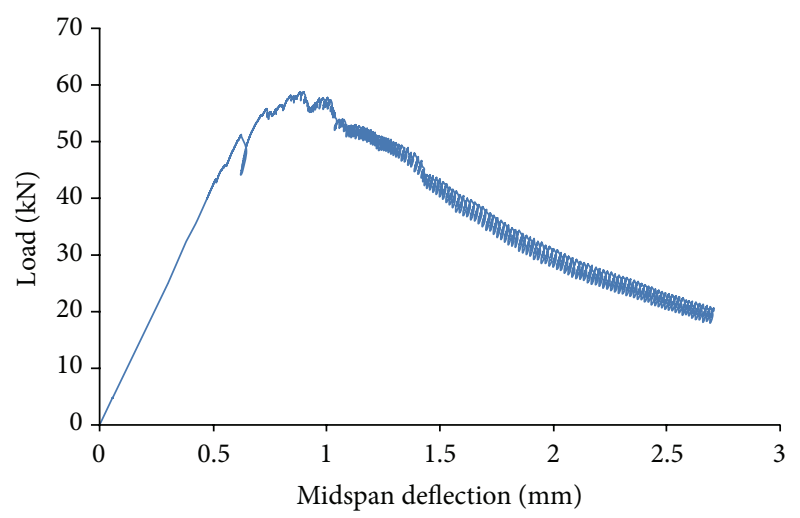

Figure 3: Flexural load-deflection curve of RPC200.

3.2.4. Failure Criterion. As for the ordinary concrete, the microcracks bifurcate or develop around the coarse aggregate and eventually turn into multiple cracking, which leads to the concrete's integral damage. In terms of RPC, strength of the matrix is high, and the binding capacity of steel fiber is relatively insufficient, so the crack rapidly propagates unsteadily once it happens. There are only one or several main cracks concentrated in the local area when RPC finally breaks up.

3.3. Frost Durability. Because the $3 \mathrm{~d}$ strength of RPC under steam curing is high, frost test and strength test were simultaneously conducted; namely, both were brought forward to $5 \mathrm{~d}$. Moreover, owing to the excellent durability of RPC, mass loss rate and relative dynamic module were tested every 50 freezing-thawing cycles. Table 4 lists the test results. The statistics reveal that the frost resisting level of RPC exceeds F300 with low mass loss rate below $1 \%$. The dynamic module changes little under freezing-thawing conditions. RPC, with its strong frost resistance durability, could guarantee itself good properties during its long service life.

\section{Structure Calculations}

RPC200 is to be used in Xialouzi Bridge reconstruction project at Xiaoying line K15 +100 on Hubei provincial road. As is shown in Figure 4, its overall width is $13.5 \mathrm{~m}$, and overall length is $18.04 \mathrm{~m}$. The upper structure is $2-5.7 \mathrm{~m}$ rectangle slab bridge and the lower is the gravity type abutment made of mortar rubble. The design load grade is V-20, T-100. The left part of the bridge was built in 1989, and its width is $7.5 \mathrm{~m}$. The concrete protective layer of the girder slab is a little thin, at the bottom of which large area of concrete spalling and steel corrosion occurred. 
TABLE 4: Frost resisting durability of RPC200.

\begin{tabular}{lccccccccccc}
\hline & \multicolumn{4}{c}{ Mass loss rate $(\%)$} & \multicolumn{4}{c}{ Relative dynamic module (\%) } \\
50 cycles 100 cycles & 150 cycles & 200 cycles & 250 cycles & 300 cycles & 50 cycles & 100 cycles & 150 cycles & 200 cycles & 250 cycles & 300 cycles \\
\hline 0.34 & 0.36 & 0.47 & 0.59 & 0.68 & 0.77 & 99.8 & 99.3 & 97.6 & 95.8 & 94.2 & 92.8 \\
\hline
\end{tabular}
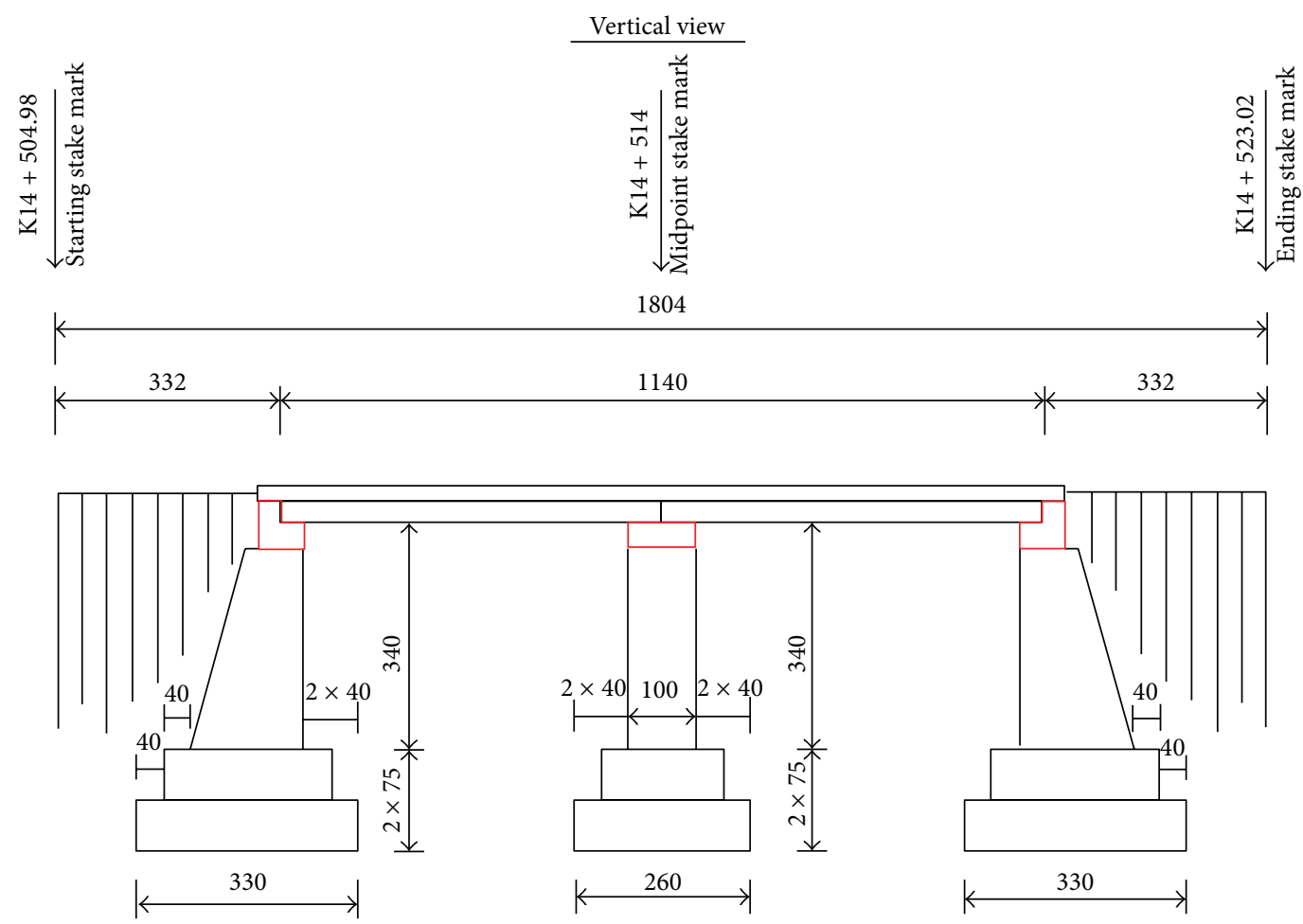

FIGURE 4: Front view of Xialouzi Bridge.

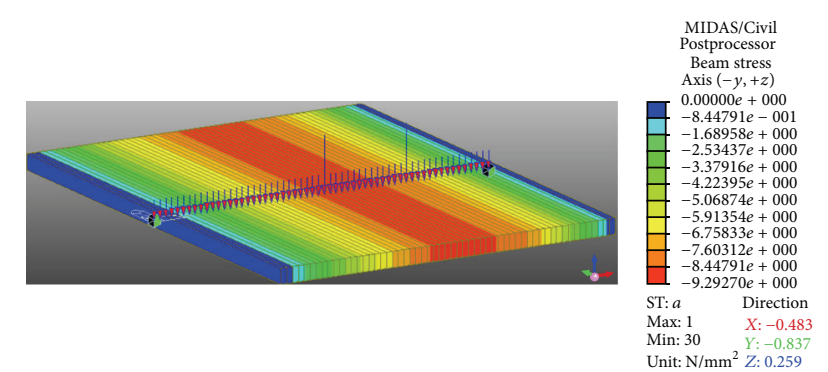

Figure 5: Calculation result of compressive stress.

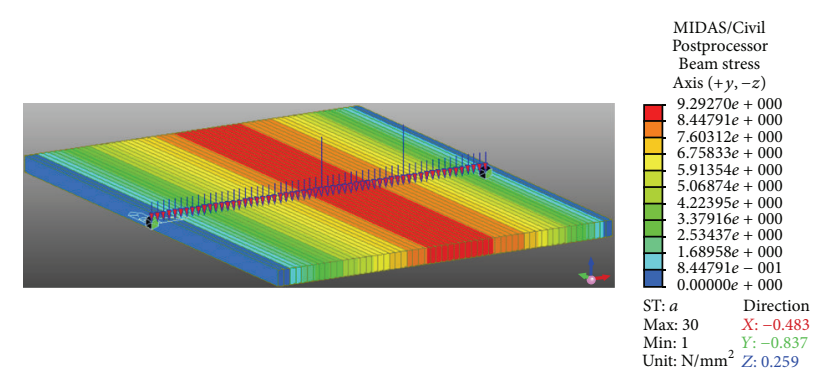

FIGURE 6: Calculation result of tensile stress.

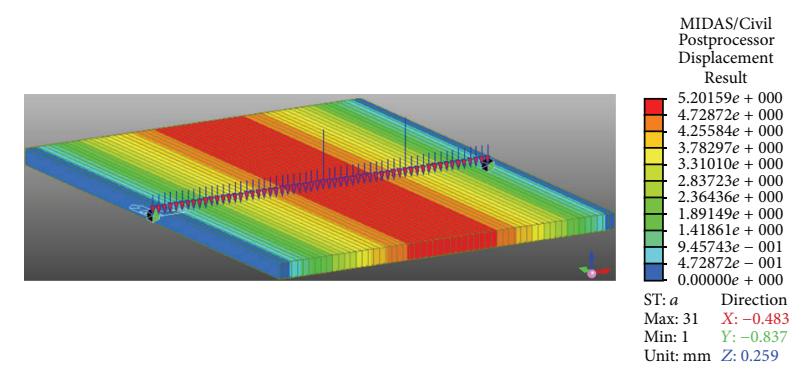

FIgURE 7: Calculation result of deflection.

Structure calculation is based on finite element method software MIDAS/Civil. The thickness of bridge deck slab is set to be $30 \mathrm{~cm}$, expanding its length from $5.7 \mathrm{~m}$ to $6.0 \mathrm{~m}$. Set the most unfavourable load and Figures 5-7 display the main calculation results. Based on the results, it could be concluded that the structure design of the whole slab is safe and reliable to meet all performance requirements:

(1) On the maximum load combination condition, the maximum tensile and compressive stress value of partial cross section in the whole slab is below $14 \mathrm{MPa}$. 


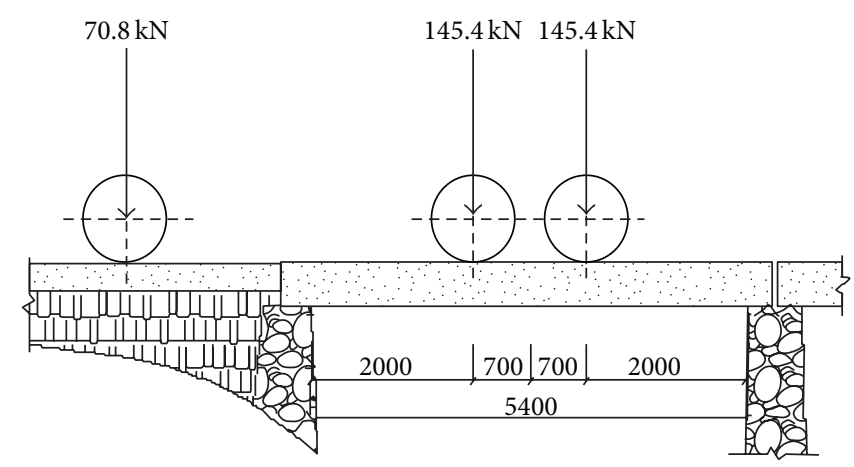

FIGURE 8: Loading trucks along the bridge's lengthways direction.

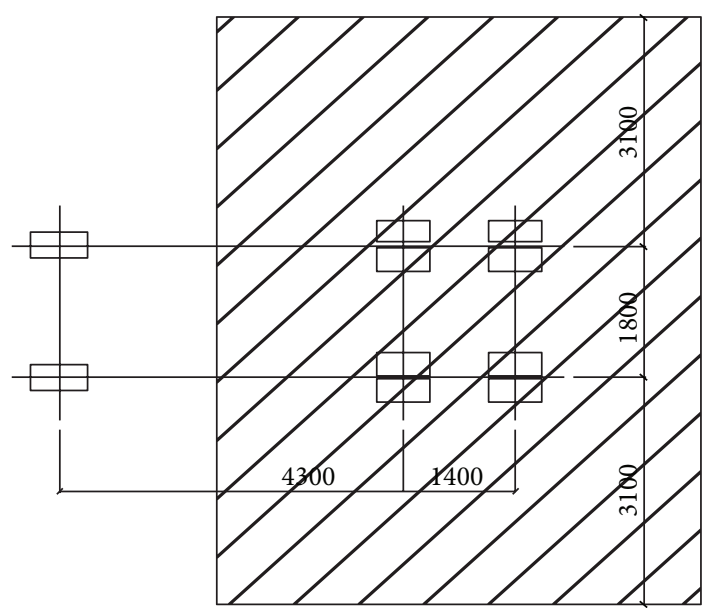

(a)

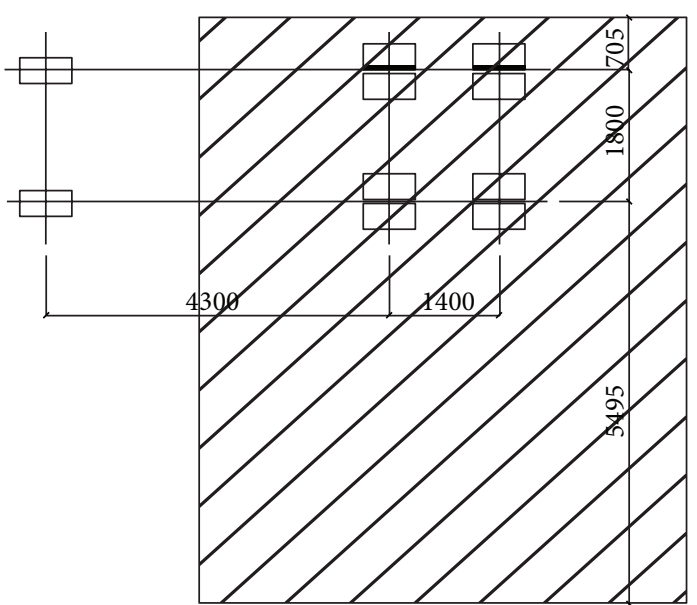

(b)

FIGURE 9: Trucks' layout of the static loading test: (a) the first condition and (b) the second condition.

Most stress values of the cross sections are below $12 \mathrm{MPa}$. Deflection of the midspan cross section is not beyond $7 \mathrm{~mm}$. The overall structure possesses a certain safety stock to meet the requirements of serviceability limit state.

(2) On the maximum load combination condition, resistances of the cross sections are all greater than the most unfavourable combination of bending moment and shearing force (absolute value). Both flexural capacity of the normal section and shear capacity of the oblique section could meet requirements of the standard.

\section{Static Loading Test}

In order to know actual force condition of the bridge's upper structure under the test loading, static loading test was conducted. It mainly consists of deflection, stress, and strain of the slab's midspan cross section under different test loadings. An 8 round self-discharging truck was employed. The loading trucks' layout along the bridge lengthways direction was set as

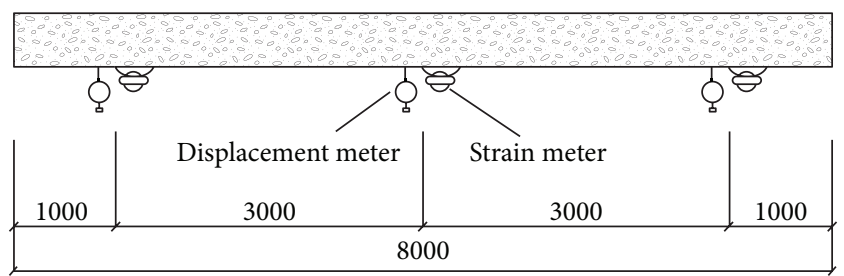

FIGURE 10: Layout of measurement points of deformation and strain on the test cross section.

shown in Figure 8 according to the worst force condition of the bridge structure considering its small span.

The upper structure of the bridge is a casting slab entirely, and the worst condition from the bridge's transverse direction is when the loading trucks locate at the center and the edge, being the first condition and second condition, respectively. Figure 9 displays specific trucks layout of each condition. Figure 10 shows the measurement points of deformation and strain on the test cross sections arrangements.

Figures 11 and 12 display the loading test results. The slab was still working in the elastic working scope under the test 


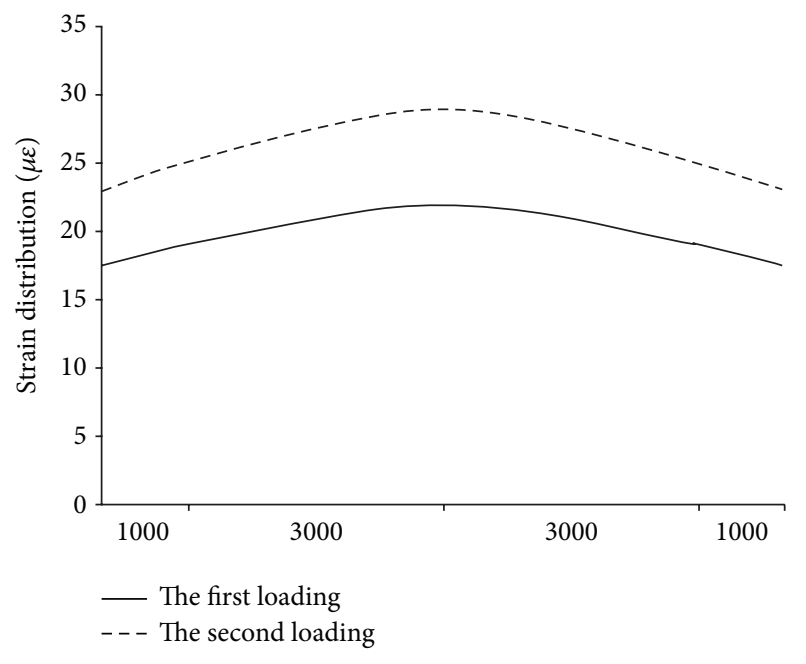

(a)

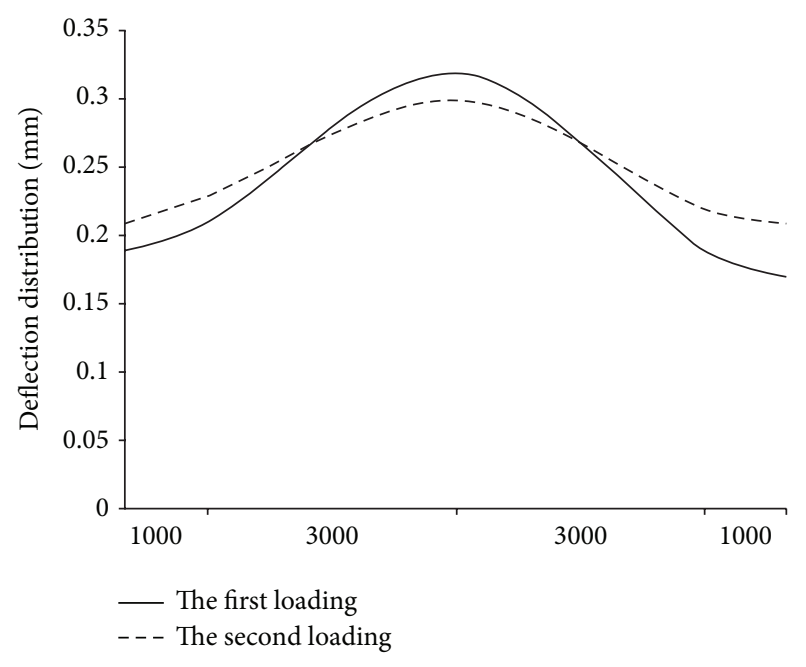

(b)

FIGURE 11: Deflection and strain distribution on the test cross section under the first condition: (a) strain distribution/ $\mu \varepsilon$ and (b) deflection distribution $/ \mathrm{mm}$.

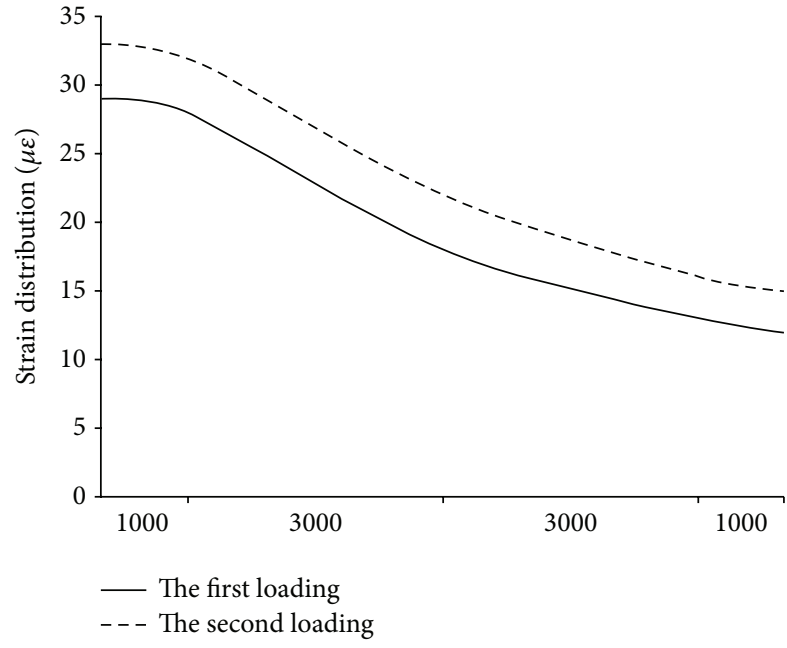

(a)

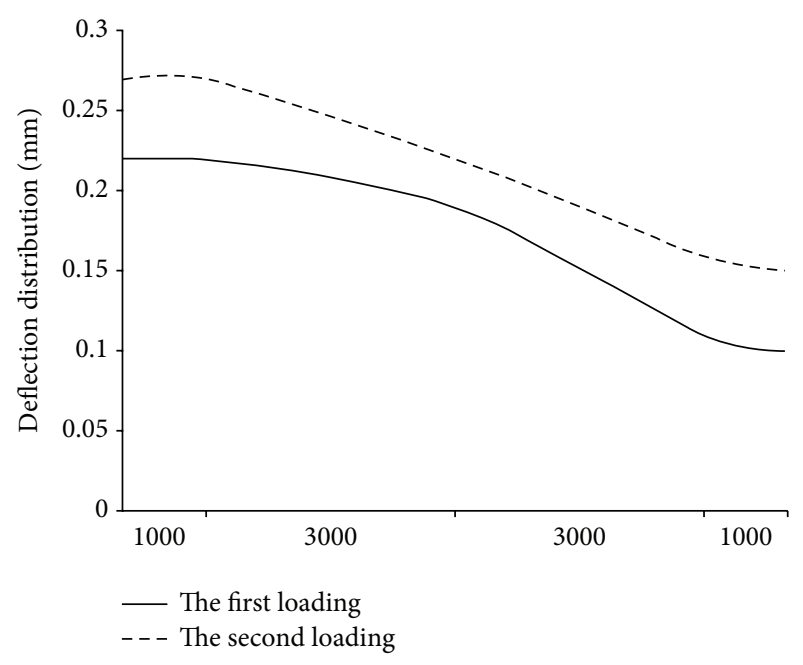

(b)

Figure 12: Deflection and strain distribution on the test cross section under the second condition: (a) strain distribution/ $\mu \varepsilon$ and (b) deflection distribution $/ \mathrm{mm}$.

loadings. Differences of deflection and strain of the twice loadings under each condition were small.

The maximum deflection was $0.32 \mathrm{~mm}$ (under the first condition), less than the admissible values in the standard $(L / 600=9.5 \mathrm{~mm})$. The maximum tensile strain at the bottom of slab was $30 \mu \varepsilon$, strain being less than the concrete ultimate tensile strain value: $100 \sim 150 \mu \varepsilon$.

Under the first condition, the distributions of deflection and strain were uniform, while, under the second condition, they are conformed to the bridge mechanical characteristics, which indicated that the upper structure was still at the elastic stage. The maximum deflection of the midspan was $0.32 \mathrm{~mm}$, far less than $L / 600$, and its maximum tensile strain was
$30 \mu \varepsilon$ far less than the concrete ultimate tensile strain. These suggest that the design of the bridge meets the utilization requirements and during the test process no crack occurred on the midspan cross section.

The Xialouzi RPC highway bridge makes full use of the advantages of ultra-high strength, toughness, and durability. The compressive and flexural strength of RPC reached up to 236.8 $\mathrm{MPa}$ and 31.4 $\mathrm{MPa}$, respectively, and its frost resisting level exceeded F300 with very low mass loss and high dynamic module. Although the bridge was built with plain RPC, it has a high bearing capacity and a long service life. Moreover, the cost is saved because the reinforcement is cancelled and the reinforcing steel bar is not used. 


\section{Conclusions}

Considering the engineering practice, it is necessary to amplify the size requirement in this paper. Ultra-highperformance material RPC was prepared under $80^{\circ} \mathrm{C}$ steam curing condition. The experiments revealed that RPC200 has high strength, tenacity, and durability. On the two stressstrain curves under different loading rates, stress of RPC200 goes linearly upward along with the increasing strain until explosive failure. Its flexural load-deflection curve shows very good ductility. The descending stage is very gentle. The extraction and tensile failure of steel fiber should account for the curve's jumping part. But as a whole the curve displays excellent tenacity. Calculation for the left of the Xialouzi Bridge, totally built by RPC, through the finite element method software MIDAS/Civil indicates that RPC is eligible to meet the requirements. Using RPC could replace the reinforcement steel bars and thus it simplifies the construction procedure. Furthermore, the excellent durability of RPC could prolong the service life of the bridge.

\section{Conflict of Interests}

The authors declare that there is no conflict of interests regarding the publication of this paper.

\section{Acknowledgments}

This project is funded by the Automobile Collaborative Innovation Project of Jiangxi University of Technology (XTCX201324), Project on Professional and Characteristic Construction of Jiangxi Province 2010 (Civil Engineering), and Project on the Planning and Construction of Disciplines in Jiangxi University of Technology (Structure Engineering).

\section{References}

[1] P. Richard and M. Cheyrezy, "Composition of reactive powder concretes," Cement and Concrete Research, vol. 25, no. 7, pp. 1501-1511, 1995.

[2] R. Yu, P. Spiesz, and H. J. H. Brouwers, "Development of an eco-friendly Ultra-High Performance Concrete (UHPC) with efficient cement and mineral admixtures uses," Cement and Concrete Composites, vol. 55, no. 1, pp. 383-394, 2014.

[3] R. Yu, P. Spiesz, and H. J. H. Brouwers, "Development of UltraHigh Performance Fibre Reinforced Concrete (UHPFRC): towards an efficient utilization of binders and fibres," Construction and Building Materials, vol. 79, pp. 273-282, 2015.

[4] S. H. Liu, P. Y. Yan, and J. W. Feng, "Research and application of RPC in the bridge engineering," Highway, vol. 58, no. 3, pp. 149-154, 2009.

[5] M. Cheyrezy, V. Maret, and L. Frouin, "Microstructural analysis of RPC (Reactive Powder Concrete)," Cement and Concrete Research, vol. 25, no. 7, pp. 1491-1500, 1995.

[6] K. Lahlou, P.-C. Aïtcin, and O. Chaallal, "Behaviour of highstrength concrete under confined stresses," Cement and Concrete Composites, vol. 14, no. 3, pp. 185-193, 1992.

[7] W. Wang, J. Liu, F. Agostini, C. A. Davy, F. Skoczylas, and D. Corvez, "Durability of an Ultra High Performance Fiber
Reinforced Concrete (UHPFRC) under progressive aging," Cement and Concrete Research, vol. 55, no. 1, pp. 1-13, 2014.

[8] A. Beglarigale and H. Yazici, "Pull-out behavior of steel fiber embedded in flowable RPC and ordinary mortar," Construction and Building Materials, vol. 75, pp. 255-265, 2015.

[9] A. Feylessoufi, F. Villiéras, L. J. Michot, P. De Donato, J. M. Cases, and P. Richard, "Water environment and nanostructural network in a reactive powder concrete," Cement and Concrete Composites, vol. 18, no. 1, pp. 23-29, 1996.

[10] A. M. Soliman and M. L. Nehdi, "Effects of shrinkage reducing admixture and wollastonite microfiber on early-age behavior of ultra-high performance concrete," Cement and Concrete Composites, vol. 46, pp. 81-89, 2014.

[11] L. Huynh, S. Foster, H. Valipour, and R. Randall, "High strength and reactive powder concrete columns subjected to impact: experimental investigation," Construction and Building Materials, vol. 78, no. 3, pp. 153-171, 2015.

[12] S. H. Liu, G. S. Xie, and M. J. Rao, "Effect of waste glass powder on properties and microstructure of ultrahigh performance cement based materials," Materials Research Innovations, vol. 17, supplement 1, pp. 210-214, 2013.

[13] R. Pierre, "Reactive powder concrete: a new ultra-high strength cementitious material," in Proceedings of the 4th International Symposium on Utilization or High Strength/High Performance Concrete, pp. 1343-1349, Paris, France, May 1996.

[14] V. Matte and M. Moranville, "Durability of reactive powder composites: influence of silica fume on the leaching properties of very low water/binder pastes," Cement and Concrete Composites, vol. 21, no. 1, pp. 1-9, 1999.

[15] R. Yu, P. Spiesz, and H. J. H. Brouwers, "Mix design and properties assessment of Ultra-High Performance Fibre Reinforced Concrete (UHPFRC)," Cement and Concrete Research, vol. 56, no. 2, pp. 29-39, 2014. 

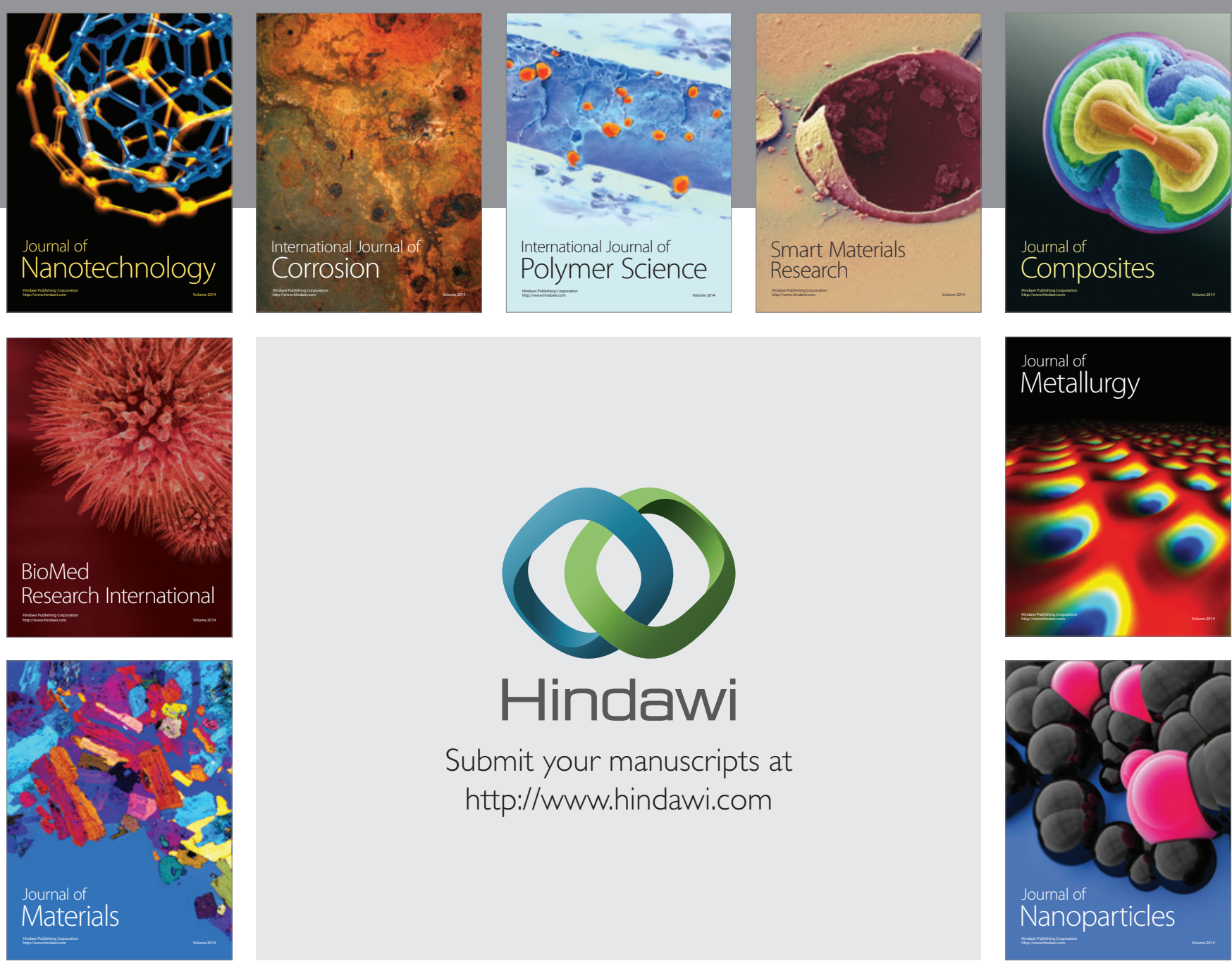

\section{Hindawi}

Submit your manuscripts at

http://www.hindawi.com

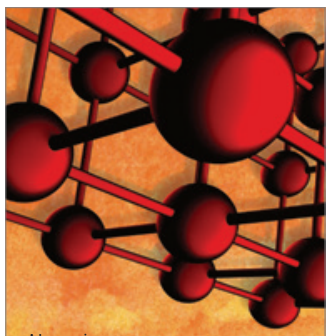

Materials Science and Engineering
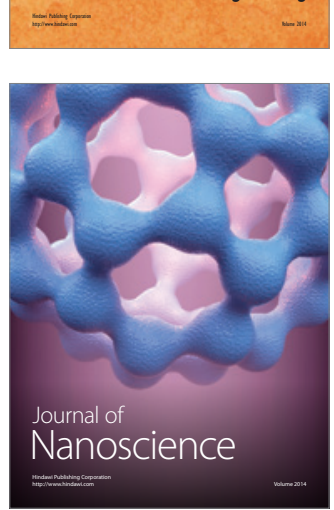
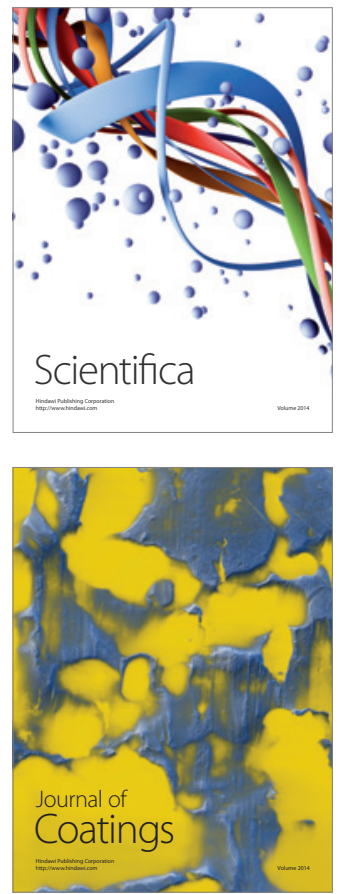
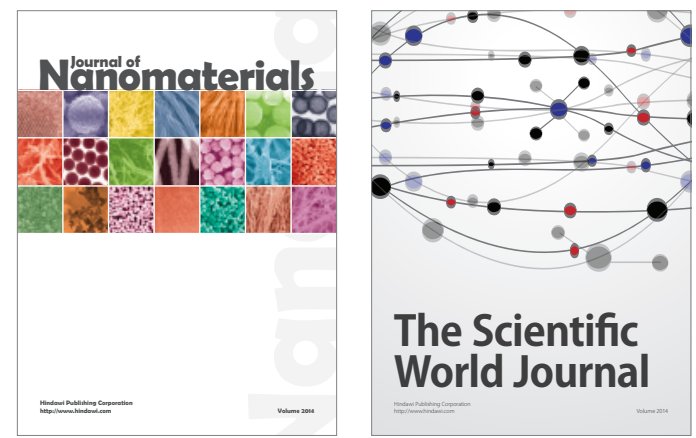

The Scientific World Journal
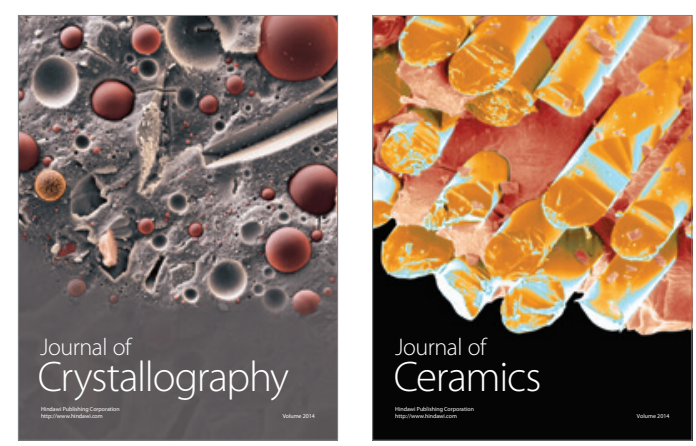
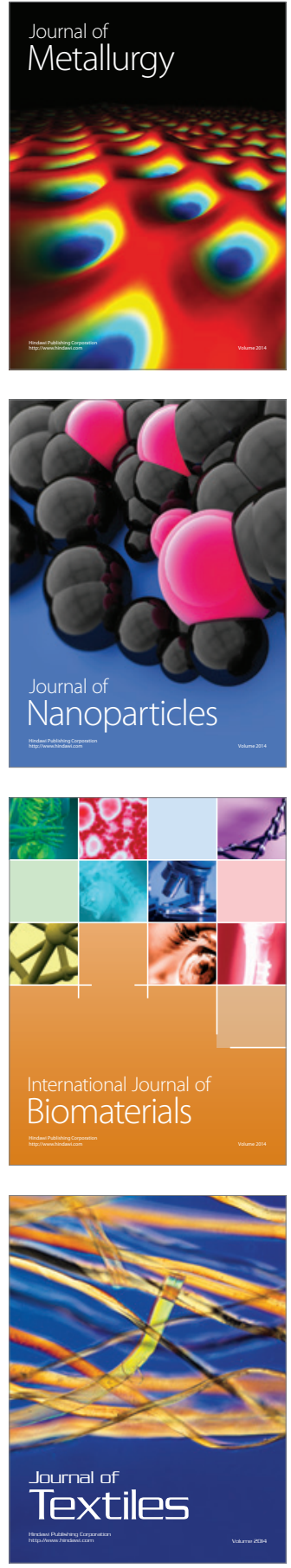